\title{
Frontières
}

\section{Suicides, générations et culture}

Volume 21, numéro 1, automne 2008

Prévenir le suicide

URI : https://id.erudit.org/iderudit/037886ar

DOI : https://doi.org/10.7202/037886ar

Aller au sommaire du numéro

Éditeur(s)

Université du Québec à Montréal

ISSN

1180-3479 (imprimé)

1916-0976 (numérique)

Découvrir la revue

Citer ce document

(2008). Suicides, générations et culture. Frontières, 21(1), 140-140.

https://doi.org/10.7202/037886ar

Ce document est protégé par la loi sur le droit d'auteur. L'utilisation des services d'Érudit (y compris la reproduction) est assujettie à sa politique d'utilisation que vous pouvez consulter en ligne.

https://apropos.erudit.org/fr/usagers/politique-dutilisation/
Cet article est diffusé et préservé par Érudit.

Érudit est un consortium interuniversitaire sans but lucratif composé de l’Université de Montréal, l'Université Laval et l'Université du Québec à Montréal. Il a pour mission la promotion et la valorisation de la recherche. https://www.erudit.org/fr/ 
VOL. 12, NO 1 AUTOMNE 1999

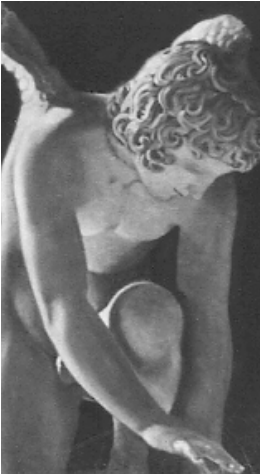

Page 3

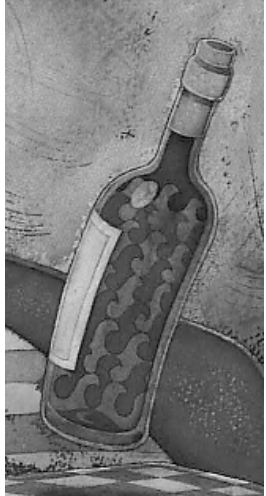

Page 69

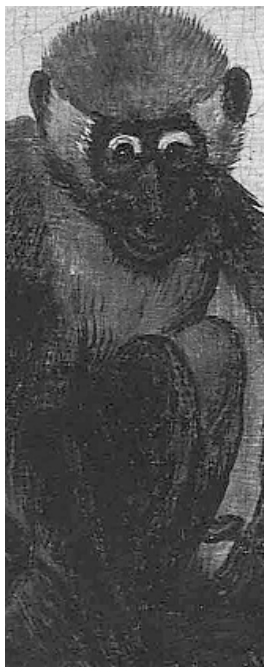

Page 104

\section{Suicides, générations et culture}

Responsable du thème, MONIQUE SÉGUIN

Coresponsable du thème, LUCE DES AULNIERS

\section{SOMMAIRE}

\begin{tabular}{ll}
\hline & ÉDITORIAL \\
3 & S'EN SORTIR \\
& LUCE DES AULNIERS \\
$\mathbf{7}$ COMMENT COMPRENDRE L'AUGMENTATION \\
DES SUICIDES AU QUÉBEC? \\
14 MICHELINE DE SĖVE \\
27 JOVETTE MARCHESSAULT \\
52 PETER F. TRENT \\
86 LUC BLANCHET \\
102 SERGIO KOKIS
\end{tabular}

PRÉSENTATION

8 SUICIDES, GÉNÉRATIONS ET CULTURE MONIQUE SÉGUIN

\section{ARTICLE DE FOND}

11 TRAJECTOIRE DE VIE ET «RÉSILIENCE» DES PERSONNES SUICIDAIRES

MONIQUE SÉGUIN

17 PEUT-ON PARLER D'UNE OBLIGATION ABSOLUE DE VIVRE?: ESQUISSE D'UNE ÉTHIQUE JUIVE ET CHRÉTIENNE JEAN-JACQUES LAVOIE

23 UNE ENTRÉE RATÉE DANS LA VIE: SUICIDES ET DYNAMIQUES SUICIDAIRES CHEZ LES JEUNES

MICHEL TOUSIGNANT, ANDRÉ GAGNON, LUCE DES AULNIERS

33 LE SUICIDE ET LES AînÉS AU QUÉBEC BRIAN L. MISHARA

39 LES CONDUITES À RISQUE SONT-ELLES DES CONDUITES SUICIDAIRES?

JOSEPH LÉVY

43 LE SUICIDE DANS LES PETITES SOCIÉTÉS MICHEL TOUSIGNANT

\section{RECHERCHE}

50 LA MORTALITÉ PAR SUICIDE AU QUÉBEC RICHARD BOYER, DANIELLE ST-LAURENT SUICIDE À L'ADOLESCENCE EN FRANCE MARIE CHOQUET SUICIDE, HOMMES ET SOCIALISATION LUCIE CHARBONNEAU, JANIE HOULE L'ALCOOLISME: UNE FORME DÉGUISÉE DE SUICIDE

LOMER PILOTE, GUY QUESNEL

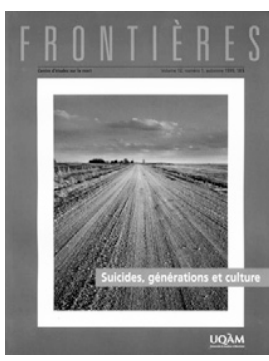

\begin{tabular}{|c|c|}
\hline & INTERVENTION \\
\hline 73 & $\begin{array}{l}\text { L'UTILISATION DU GÉNOGRAMME DANS } \\
\text { LA CLINIQUE DU SUICIDE } \\
\text { NORMAND D'ARAGON }\end{array}$ \\
\hline 79 & $\begin{array}{l}\text { MIEUX COMPRENDRE POUR MIEUX } \\
\text { INTERVENIR AUPRĖS DU JEUNE SUICIDANT } \\
\text { RÉAL LABELE, } \\
\text { AVEC LA COLLABORATION DE RICHARD BOYER }\end{array}$ \\
\hline 84 & $\begin{array}{l}\text { DE L'INNOCENCE À LA TRAGÉDIE: } \\
\text { LE DEUIL DES ENFANTS SUITE AU SUICIDE } \\
\text { D'UN PROCHE } \\
\text { SYLVIE HINTON, MONIQUE SÉGUIN }\end{array}$ \\
\hline 89 & $\begin{array}{l}\text { LE MILIEU COMMUNAUTAIRE ET LA PRÉVEN- } \\
\text { TION DU SUICIDE AU QUÉBEC } \\
\text { SYLVAINE RAYMOND }\end{array}$ \\
\hline 94 & $\begin{array}{l}\text { LES NIVEAUX DE RESPONSABILITÉ DANS } \\
\text { L'INTERVENTION: L'EXEMPLE DU SUICIDE } \\
\text { EN MILIEU CARCÉRAL } \\
\text { MARC S. DAIGLE }\end{array}$ \\
\hline 100 & $\begin{array}{l}\text { POINT DE VUE } \\
\text { LA MÉDIATISATION DU SUICIDE } \\
\text { HÉLĖNE BÉLANGER }\end{array}$ \\
\hline 104 & $\begin{array}{l}\text { DISCOURS, PRATIQUES ET AFFOLEMENT } \\
\text { AUTOUR DU SUICIDE AU QUÉBEC } \\
\text { PIERRE MIGNEAULT }\end{array}$ \\
\hline
\end{tabular}
REGARD

108 GISELLE D'ICI: UN BALLET AU-DELÀ DE L'ART, UN OUTIL DE PRÉVENTION NADIA CHAWKY

HORS THÈME

111 ÊTRE OU AVOIR, VOILÀ LA TENSION... DANIEL LAGUITTON

\begin{tabular}{|c|c|}
\hline 115 & $\begin{array}{l}\text { LECTURES } \\
\text { PIERRE FORTIN ET BRUNO BOULIANNE } \\
\text { LE SUICIDE, INTERVENTIONS ET ENJEUX } \\
\text { ÉTHIQUES }\end{array}$ \\
\hline 115 & $\begin{array}{l}\text { MARC CHABOT } \\
\text { EN FINIR AVEC SOI }\end{array}$ \\
\hline 116 & $\begin{array}{l}\text { DANIEL BORDELEAU } \\
\text { FACE AU SUICIDE }\end{array}$ \\
\hline 116 & $\begin{array}{l}J E A N-M A R C D U F O R T \\
\text { EUTHANASIE ET AIDE AU SUICIDE }\end{array}$ \\
\hline 118 & $\begin{array}{l}\text { MARIE-LINE MORIN } \\
\text { LE SUICIDE CHEZ LES JEUNES }\end{array}$ \\
\hline 119 & $\begin{array}{l}\text { ANDRÉ BERGERON ET ÉRIC VOLANT } \\
\text { LE SUICIDE ET LE DEUIL }\end{array}$ \\
\hline $\begin{array}{l}120 \\
123\end{array}$ & $\begin{array}{l}\text { BIBLIOGRAPHIE } \\
\text { NOUVELLES PARUTIONS }\end{array}$ \\
\hline
\end{tabular}

